Revista de Literatura, História e Memória

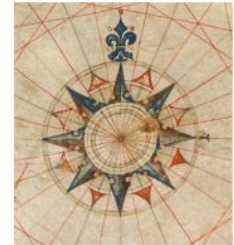

Dossiê: Feminismos e literaturas

ISSN 1983-1498

VOL. 17 - No 30 - 2021

U N I O E S T E / CA S C A V E L - p. 211-222

\title{
DESCOLONIZANDO CORPOS E SUBJETIVIDADES: REPRESENTAÇÕES FEMININAS EM AMORES INSÓLITOS DE NUESTRA HISTORIA (2011)
}

Decolonizing bodies and subjectivities:

female representations in Amores insólitos de nuestra historia (2011)

\section{Maria de Fátima Alves de Oliveira Marcari ${ }^{1}$}

RESUMO: Na coletânea de contos Amores insólitos de nuestra historia (2011), a escritora argentina Maria Rosa Lojo reelabora as histórias individuais e coletivas de personagens que foram subalternizadas pelo discurso histórico hegemônico: indígenas, mestiças e cativas; fundadoras de uma Argentina transculturada, construída em boa parte graças às mestiçagens e alianças de culturas e etnias. Nosso trabalho objetiva analisar como a escritora ressignifica as subjetividades femininas, por meio de narrativas em que o corpo forma parte do processo de articulação dos sujeitos femininos que se opõem à colonialidade de gênero. Assim, as narrativas questionam a concepção patriarcal do corpo feminino como território a ser conquistado, reconhecendo-o como um locus de emancipação e de constituição de subjetividades. Outrossim, analisamos como as narrativas recuperam figuras subalternizadas sem vitimizá-las ou idealizá-las, subvertendo não apenas o discurso patriarcal, mas também o projeto nacional argentino que se assumiu como etnicamente branco, e que buscou minimizar o papel das mulheres, além de tentar apagar os indígenas e outras minorias étnicas da história nacional. Contamos com o apoio teórico dos estudos de Lugones (2019), Mignolo (2020) e Bordieu (1999).

PALAVRAS-CHAVE: Maria Rosa Lojo (1954-); Subjetividade; Corpo; Decolonialidade; Gênero.

ABSTRACT: Argentine writer Maria Rosa Lojo's Amores insólitos de nuestra historia (2001) is a short story collection in which she re-elaborates both individual and collective memories of characters who were subordinated by the hegemonic historical discourse: indigenous, mestizo, and captives, women founders of a transcultural Argentina, built largely thanks to cultures and ethnicities' miscegenation and alliances. This research was carried out to analyze how Rojo resignifies female subjectivities, through narratives in which the articulation process of female subjects who are opposed to male domination is formed by the body. Thus, the narratives question the female body as a territory to be conquered, as conceived by the patriarchy, recognizing it as a locus of emancipation and constitution of subjectivities. Furthermore, we analyze how the narratives recover subaltern figures without victimizing or idealizing them, subverting not only the patriarchal discourse but also the Argentine national project, that assumed itself as ethnically white, and that sought to minimize the role of women, in addition to erasing the indigenous and other ethnic minorities of the national memory. The theoretical framework is composed of studies by de Lugones (2019), Mignolo (2020) and Bordieu (1999).

KEYWORDS: Maria Rosa Lojo (1954-); Subjectivity; Body; Decoloniality; Genre.

\footnotetext{
${ }^{1}$ Professora Assistente do Depto. de Letras Modernas da Universidade Estadual Paulista/Faculdade de Ciências e Letras de Assis (UNESP/Assis). Professora do Programa de Mestrado e Doutorado em Letras - Literatura e Vida Social.
} 


\section{INTRODUÇÃO}

Poeta, romancista, contista, ensaísta e pesquisadora, María Rosa Lojo (1954-) é uma das mais importantes escritoras da atualidade. Poucas intelectuais possuem um vínculo tão profundo entre suas obras de ficção e de investigação como a autora argentina. Sua obra crítica, bem como grande parte de sua obra ficcional, elabora uma revisão da história, da identidade nacional argentina e de seus mitos fundacionais, por meio de uma releitura do passado argentino, ao dar voz àqueles que foram apagados e/ou silenciados tanto do arquivo histórico quanto do arquivo literário nacional. Nesta perspectiva, a autora “(...) vem produzindo há três décadas uma obra multifacetada que circula entre a ficção, a história e a memória" (ESTEVES, 2016, p. 69), em um vasto rol de produções: microficções líricas/poemas em prosa, romances, contos e ensaios.

Na coletânea de contos Amores insólitos de nuestra historia, publicada pela primeira vez em 2001 e ampliada em sua segunda edição em 2011, observa-se a configuração de uma série de representações femininas que problematizam os lugares e os papéis atribuídos às mulheres nas relações sociais na Argentina do século XIX. As narrativas retratam relações amorosas cujo caráter insólito deve-se à disparidade dos amantes, marcados pela censura social e sobretudo pelo desnível com relação ao poder. Tal desnível caracterizou as relações de mestiçagem que fundaram nossas sociedades coloniais, não apenas na Argentina retratada pela escritora, mas em toda a América Latina. A herança da matriz colonial hispânica sustentada fundamentalmente sobre padrões étnicos racistas - seguiu atuando como um dispositivo de controle das relações sociais, econômicas, políticas e de gênero.

Walter Mignolo (2020, p. 39) denomina esse dispositivo de controle de colonialidade do poder, lugar epistêmico de enunciação em que se descreve e se legitima o poder patriarcal e colonial. Tais poderes definiram não apenas essas relações sociais, mas também as subjetividades e os corpos, marcados pela diferença colonial, que consiste em classificar pessoas ou mesmo populações e identificá-los em suas "faltas ou excessos", o que marcaria a diferença e a inferioridade desses grupos com relação a quem os classifica.

Ampliando as teorizações de Mignolo, a socióloga argentina María Lugones (2019) busca entender a opressão das mulheres que foram subalternizadas por meio da combinação de processos de racialização, colonização, exploração capitalista e de gênero. A teórica denomina essas opressões de colonialidade dos gêneros, bem como a possibilidade de superar tais opressões é o que preconiza o feminismo decolonial. Assim sendo, Lugones (2019) introduz o conceito de 'subjetividade ativa' para identificar um senso mínimo de agência das 
pessoas que resistem a múltiplas opressões, cujas subjetividades também múltiplas são reduzidas por noções hegemônicas, coloniais e atribuídas de raça e gênero. A resistência à colonialidade dos gêneros ocorre por modos de resistência performados por sujeitos ativos, construídos pelo habitar da diferença colonial como um locus fraturado (LUGONES, 2019, p. 374).

Neste contexto, e contrapondo-se a sociedade patriarcal que prescreve a colonização dos corpos subalternizados (especialmente o corpo feminino), as narrativas de Maria Rosa Lojo configuram protagonistas femininas como sujeitos heterogêneos, plurais, cujas subjetividades se constroem em relações e negociações com outros sujeitos, com os espaços que habitam, e inseridas nas relações de poder, às quais respondem, muitas vezes, de maneira resistente, embora nem sempre como um desafio aberto. Por conseguinte, as teorizações sobre as corporalidades e as subjetividades decoloniais ecoam nas narrativas de Maria Rosa Lojo, nas quais as personagens femininas assumem um protagonismo marcante em praticamente todos os relatos. No presente artigo, analisamos brevemente a trajetória das protagonistas de quatro relatos da coletânea: El maestro y la reina de las amazonas, Otra historia del guerrero y la cativa, Té de araucaria e Mirándola dormir.

\section{CORPOS RESISTENTES: GUERREIRAS E CATIVAS}

No relato intitulado El maestro y la reina de las Amazonas, vemos a reelaboração ficcional de um episódio sobre a guerrilheira Martina Chapanay (1800-1874), personagem histórica que lutou, ao lado de seu companheiro Chacho Peñaloza (1798-1863) e do caudilho Facundo Quiroga (1788-1835), nas guerras entre unitários e federalistas na Argentina. Na narrativa de Lojo, ela sequestra um professor de uma escola primária da província de San Juan para que ele possa ensiná-la a ler e a escrever. A história do encontro entre o professor e a fascinante combatente é apócrifa; contudo, inspira-se nos relatos sobre a liberdade com que Martina Chapanay viveu sua vida sexual após a morte de Peñaloza em combate, quando passou a escolher livremente seus companheiros ocasionais, inclusive entre suas vítimas.

O jovem professor capturado escolhe a obra Facundo o civilizacion y barbarie $(1845)^{2}$, considerada uma narrativa fundadora da identidade argentina, para ensinar as

\footnotetext{
${ }^{2}$ Em Facundo o civilización y barbarie (1845), Domingo Sarmiento descreve a geografia física pampeana e seu isolamento como fatores que influenciariam a personalidade do argentino interiorano, partindo dos pressupostos deterministas vigentes no século XIX. Contrapõe a vida urbana com a vida no campo, ressaltando o aspecto "civilizado" da primeira em contraste à "brutalidade primitiva" da última. Registra uma tipologia de gauchos: o o rastreador, o baqueano, o gaucho malvado e o cantor. A segunda parte é a biografia
} 
primeiras letras a Martina. No entanto, é ela quem dá aulas ao professor, ao revisar aspectos da história argentina narrados na obra pelo escritor Domingo Sarmiento, contrapondo, assim, sua memória testemunhal ao texto canônico do autor. Ela faz reparos à imagem de Facundo Quiroga, -retratado como a encarnação da barbárie por Domingo Sarmiento -, destacando sua atuação como líder da causa federalista e defensor dos interesses das províncias na exploração das minas: "Quanto a Quiroga, era melhor que as minas estivessem em nossas mãos e não nas dos portenhos ou dos gringos" (LOJO, 2011, p. 139, trad. nossa). Martina destaca o papel do caudilho, que sempre esteve à frente das batalhas; contudo, enfatiza que todos lutavam "para que pudéssemos respirar sem pedir permissão aos portenhos" (LOJO, 2011, p. 139, trad. nossa), e não por subordinação ao caudilho Facundo Quiroga.

A protagonista revisa criticamente os três capítulos em que o autor elabora uma tipologia do gaucho argentino, evidenciando a importância de sua biografia pessoal frente ao discurso de Sarmiento: "Se o senhor Sarmiento tivesse me conhecido, poderia ter resumido os três capítulos em um só. Tanto guiei tropas como busquei homens e animais, assim como também os roubei. Claro que se tivesse me mencionado, nem os portenhos nem os gringos teriam acreditado nele" (LOJO, 2011, p. 140, trad. nossa). Desse modo, ao contrapor seu relato testemunhal ao discurso hegemônico, a personagem elabora uma contra-história, uma forma de resistir ao silenciamento e, sobretudo, ao apagamento dentro das formas dominantes de representação histórica das subalternidades.

Se as lendárias amazonas eram guerreiras que formavam um matriarcado em que capturavam os homens apenas para fins de procriação, a amazona Martina Chapanay atualiza o mito, ao atuar ao lado dos homens em causas comuns, como a luta federalista liderada pelo caudilho Facundo Quiroga contra o poder unitário de Buenos Aires. Em sua releitura do mito, Maria Rosa Lojo elabora a história de uma rainha das amazonas que não eliminou os homens para se destacar em um contexto patriarcal, e tampouco abdicou de sua feminilidade, pois conservou "seus peitos jovens, inteiros e perfeitos" (LOJO, 2011, p. 145, trad. nossa), ao contrário das lendárias amazonas, conforme constata o professor com admiração.

Não ocorre, portanto, uma negação do corpo sexuado, mas sim um trabalho constante de ressignificação de seu valor simbólico, que coloca em relevo vários elementos corporais,

de Facundo Quiroga, líder da causa federalista, que encarnaria a barbárie que impediria o progresso da nação argentina. Contudo, o autor descreve de modo ambivalente a vida e os feitos de Facundo Quiroga, alternando entre a admiração e a repulsa. Nos demais capítulos, narra as lutas pela independência e os posteriores conflitos entre unitários e federalistas. Enquanto os unitários defendiam a centralização do poder em Buenos Aires, os federalistas buscavam a autonomia das províncias. 
tais como "a cabeleira grossa e reluzente" de Martina, símbolo da força e, ao mesmo tempo, da feminilidade da protagonista, assim como seu corpo, cujas formas "negras e duras, esculpidas e disciplinadas pelo trabalho, não the haviam permitido transbordar-se em carnes" (LOJO, 2011, p. 135, trad. nossa). Desse modo, o relato considera o corpo da mulher como primeiro lugar de resistência à colonialidade de gênero, a partir de novas formas de expressão. A partir da ocupação de um locus fraturado, a personagem expressa formas criativas de atuar e se relacionar, que são antitéticas à lógica do capital, bem como sua relação com a cultura e a natureza expressam saberes inapreensíveis por uma racionalidade moderna fechada em si mesma. Assim sendo, Martina atuou como uma espécie de Robin Hood, que assaltava os fazendeiros ricos para repartir com os pobres o produto de suas pilhagens; como a mulher ousada que raptava homens para convertê-los em seus amantes; como guia e rastreadora infalível que conhecia como ninguém os pampas e, finalmente, como a curandeira, a índia huarpe que curava os enfermos com ervas e infusões, conforme recorda o narrador nas páginas finais do conto, quando visita o famoso túmulo da guerrilheira.

Desse modo, o relato recupera a importância histórica da figura de Martina Chapanay, que, assim como muitas figuras femininas e subalternizadas da história argentina e latinoamericana, foi objeto de apagamento e eliminação simbólica pela historiografia tradicional.

Conforme afirma Maria Rosa Lojo (2000, p. 7), ao longo da história patriarcal latinoamericana, a mulher surge descrita sobretudo como sujeito situado entre a natureza e a cultura, a civilização e a barbárie, cuja fragilidade lhes conferiria um lugar instável. Nesta perspectiva, as primeiras representações simbólicas do corpo da pátria na literatura argentina foram as representações dos corpos das cativas, mulheres raptadas por índígenas, forçadas a deixar o âmbito da civilização familiar e passar para o outro lado; para a chamada barbárie. Ao lado do gaucho, a cativa representou um mito fundador da literatura nacional, que deu origem a um ciclo escritural e discursivo cujo alcance foi além das expressões canônicas do século XIX.

Em um país no qual sempre se tentou definir as fronteiras que separam a civilização da chamada barbárie, a modernidade da tradição e o perfil étnico europeu do nativo, o corpo da cativa, cujo capital reprodutivo está ameaçado pela "contaminação" do sangue do selvagem, é o lugar simbólico onde se joga o destino da identidade nacional, porque é onde se concentra o drama da mestiçagem, da desterritorialização forçada e da transgressão. (ROTKER, 1999).

Assim sendo, Maria Rosa Lojo reelabora, em pleno século XXI, esse arquétipo fundacional da literatura argentina em seu relato Otra historia del guerrero y la cautiva, que narra a história da jovem Dorotea, raptada ao catorze anos pelos índios ranquéis durante um 
assalto indígena. Após o rapto, a cativa passa a viver como agregada na aldeia de um cacique. Com a morte da terceira esposa do chefe indígena, e após lutar contra as outras agregadas que queriam cortar suas tranças, Dorotea desperta a atenção do cacique, devido a sua beleza e valentia, e é escolhida para ser sua nova esposa. Cabe ressaltar que a autora se preocupa em retratar a estrutura social das tribos ranquéis, nas quais a autoridade não era exercida exclusivamente pelos caciques, mas também pelas machis, curandeiras que eram respeitadas por todos. Ao retratar o chefe indígena como um homem amável e inteligente, que seguia os conselhos da velha curandeira de sua tribo, Lojo inverte a ideologia colonial que reduzia o indígena a um ser selvagem, pertencente a uma suposta sociedade bárbara (MARCARI, 2016, p. 50).

A narrativa também apresenta a história de um suposto guerreiro: Lisandro Cáceres, um jovem que se alista na histórica Campanha do Deserto (1879), formada por incursões militares contra os povos mapuche, tehuelche e ranquel, com o objetivo de obter o domínio territorial do pampa argentino, até então sob controle indígena. Lisandro considera o pampa como um "cárcere sem portas", onde penetra apenas durante as incursões militares. Ele se adapta à duríssima disciplina militar; no entanto, sente-se como um estrangeiro entre dois mundos. Assim, o soldado é o verdadeiro cativo e não Dorotea, uma vez que ele "se acomoda a estar preso no fio da fronteira," em um entre-lugar "que saltava adiante ou para trás, ao ritmo das derrotas ou das vitórias" (LOJO, 2011, p. 224, trad. e grifos nossos). A fronteira é a linha que oscila, passando a configurar uma territorialidade física e simbólica porosa, maleável, múltipla e complexa, tal como foi a fronteira sul argentina.

Dorotea, por sua vez, consegue habitar a fronteira, caracterizando-se como uma personagem transculturada, situada entre duas culturas, constantemente mediando entre elas e conquistando seu espaço na comunidade indígena, como esposa do cacique e sua ministra. $\mathrm{O}$ relato, portanto, encena modos de resistência performados pela ex-cativa, constituídos pelo habitar da diferença colonial como um locus fraturado (LUGONES, 2019).

Ela passa, portanto, a habitar um locus fraturado, construído duplamente, relacionandose com os dois 'lados' que estão em tensão, e o próprio conflito configura a subjetividade do eu colonizado em relações múltiplas. Através da escrita, Dorotea/Lucero Rojo conquista o espaço público da comunidade indígena, atuando como uma mediadora nos acordos entre os indígenas e os brancos. Contudo, no final do relato, os soldados da Campanha do Deserto atacam e exterminam a aldeia, bem como resgatam a cativa. Ao ser questionada se estava feliz por poder voltar à “civilização", Dorotea/Lucero Rojo desafia o coronel que efetua seu resgate - o qual ela considera uma captura - e afirma sua nova identidade indígena: "Tenho filhos 
índios. (...). Agora eu também sou índia (...). Esqueci os cristãos, assim como eles me esqueceram por tanto tempo.(...) Não tenham ilusões. Os senhores não valem para eles muito mais do que nós" (LOJO, 2011, p. 233, trad. nossa).

Durante a longa viagem de volta, Dorotea sofre uma tentativa de estupro por parte de Lisandro, mas ela resiste e luta ferozmente com ele. Após ter avaliado sua situação, ela procura Lisandro alguns dias depois e pede para que ele a ajude a esconder-se junto com seus filhos em um povoado vizinho, até que ele possa pedir baixa do Exército e passar a viver com ela.

Dorotea decide então passar a noite com o soldado, demonstrando ser sujeito e não objeto do desejo masculino. Lisandro se oferece para casar-se com ela - o que ele considera como uma reparação simbólica - , com a condição de que ela assuma que foi sempre forçada a se submeter ao cacique. Mas a ex-cativa afirma a autonomia de seu corpo e de seu desejo, não aceitando ser reduzida a um corpo colonizado. Contudo, os dois são descobertos pelas autoridades e ela é obrigada a voltar para seu antigo povoado com seus filhos, enquanto Lisandro é obrigado a pedir sua baixa do exército.

A ficcionalização da história de Dorotea recupera a figura histórica das cativas que não tiveram voz no mundo letrado, subvertendo o discurso patriarcal vigente no século XIX, pois seu comportamento e suas palavras questionam e tentam resistir ao poder colonial. Assim sendo, a figura da cativa, considerada historicamente como um objeto a ser resgatado, e também foco de sedução erótica, na verdade cumpre um papel político, pois se situa em um vínculo com os interesses em luta. "O papel de mediadora, com todos os seus riscos, já se mostra como o difícil destino dessas mulheres, que muitas vezes vão se apoderar deste papel e desempenhá-lo com inteligência e relativa autonomia” (LOJO, 2000, p. 13, trad. nossa).

\section{CORPOS DISCIPLINADOS: DA SUBMISSÃO Á EMANCIPAÇÃO}

Vistos historicamente, o disciplinamento e a normatização dos corpos se configuraram como estratégias duráveis e flexíveis de controle social desde a época colonial. A imposição colonial moderna de um sistema opressor, racialmente diferenciado, hierárquico e de gênero segue presente na lógica moderna das dicotomias, nas estratégias sociais de coerção e disciplinamento dos corpos femininos, cujas forças e energias estão habituadas ao controle externo, à sujeição e ao aperfeiçoamento. Nesta perspectiva, analisamos dois relatos - Té de araucaria e Mirándola dormir -, que retratam como a dominação patriarcal "adestra" o corpo feminino, isto é, de que forma o corpo feminino se torna colonizado, ou seja, modelado e 
controlado pelo masculino.

Té de araucaria (Chá de araucária) narra a história da personagem Manuela Namuncurá, ou Lady Cavendish, neta fictícia do cacique Manuel Namuncurá (1811-1908), líder da nação indígena mapuche. A jovem Manuela se casa ainda na adolescência com um nobre inglês muito mais velho que ela. Seu marido a chama de Dolly, pois nunca consegue pronunciar seu nome corretamente. Durante uma de suas costumeiras viagens para o litoral, ela passa as tardes jogando pôquer com um grupo de senhoras. Ao voltar dessas reuniões, ela detém seu olhar com estranheza sobre os objetos da casa de veraneio onde passam férias, e constata que havia se acostumado com o fato de que nada daquela casa, e sequer de sua casa em Londres, fosse seu por muito tempo e nem por inteiro; nem sequer seu marido, sempre gentil, mas distante.

Para que ela se sentisse menos solitária, o marido contrata uma criada índia, vinda de uma terra que não era mais sua, invadida pelos brancos na guerra contra os indígenas. A criada quase não fala, apenas sussurra numa língua antiga, sua língua materna, que Manuela acredita às vezes reconhecer. Numa tarde, antes de deitar-se para sua costumeira siesta após o almoço, a criada lhe serve um chá de folhas de araucária, árvore sagrada dos índios mapuches, que tinha funções medicinais "para o corpo e para o espírito, para o amor e para o sono, para meditar, para esquecer e para recordar" (LOJO, 2011, p. 253, trad. nossa), segundo a velha senhora. Ao escutar a mulher cantando, Manuela reconhece as palavras de uma canção que ela mesma cantava, do outro lado do mundo, quando era criança.

O chá de araucária desperta as reminiscências de Manuela, descolonizando sua memória, após um sono profundo, em que rememora seu passado como princesa araucana. Seu pai havia morrido numa batalha e sua mãe andava ocupada com muitos filhos e inúmeras tristezas. Após a trégua histórica pactuada pelo seu avô, o cacique Manuel Namuncurá, com os brancos, Manuela passou a ser um sujeito colonizado, praticamente um objeto de troca, ao deixar sua terra e casar-se ainda adolescente com um homem maduro e mudar-se para a Inglaterra, abandonando suas crenças e costumes.

Sua trajetória exemplifica o projeto de transformação civilizatória, que justificou a colonização da memória, e, junto dela, a do entendimento das pessoas sobre si mesmas, sobre suas relações intersubjetivas, suas relações com o mundo espiritual, com a terra, com a identidade e a organização social. Dolly/Manuela passa então a questionar a identidade que assumiu sob a tutela do marido já há dez anos. Constata que Lord Cavendish se apoderou dela como um colecionador que recolhe objetos raros que poderiam ser de muito proveito, após um polimento e posterior exibição em uma vitrine que realçasse seu valor diante dos olhos dos 
amigos.

Seu marido a chamava de Dolly por considerá-la uma boneca viva, um ser passivo e decorativo a ser exibido na vitrine que era a sala de sua casa em Londres. Em reuniões com os amigos do marido, ela costumava fazer uma entrada teatral, vestida com seu traje de lã negra, uma faixa colorida na cintura e todas as suas pesadas joias de prata lavradas pelos artesãos de sua terra. Logo Manuela se cansou e interrompeu definitivamente aquelas exibições como uma exótica peça de museu aos convidados, bem como cortou as longas tranças negras, o que causou um desgosto mal disfarçado no marido.

A jovem decide assumir sua identidade como Lady Cavendish e passa a usar vestidos de seda branca que, para as outras senhoras, contrastavam demasiadamente com sua pele escura. Nota-se que o corpo subalterno está sempre inscrito em um sistema de relações de poder que o classificam e o narram. Ao ter sua subjetividade colonizada e fragmentada pelo exílio e pelos vários papéis que deveria desempenhar, Manuela passa a ser vista pelo marido como Dolly, objetificada como uma boneca, e também Lady Cavendish, a jovem dama da sociedade mal vista pelas demais mulheres devido à cor de sua pele.

Manuela/Dolly/Lady Cavendish se conscientiza de sua configuração como sujeito colonizado, refém dessas classificações que tentam disciplinar o seu corpo, objetificando-a através do papel de boneca, vestida com os trajes mapuches, ou usando o "disfarce" de dama da sociedade inglesa. Por meio do chá de araucária, ela recupera sua identidade como Manuela Namuncurá e tem acesso às suas memórias mais recônditas. Resolve então partir, levando todas as suas vestimentas antigas e as pesadas joias de prata, não se esquecendo dos cheques que ganhou nas partidas de pôquer.

Observa-se inicialmente que a personagem se configura como um corpo dócil, objetificada por meio da violência simbólica, a qual, segundo Bordieu (1999, p. 50), é uma forma de poder que se exerce sobre os corpos sem qualquer coação física, e que se manifesta de maneira invisível e insidiosa através da dominação masculina. Contudo, Manuela é portadora de uma subjetividade nômade e multifacetada que, mesmo submetida às estruturas patriarcais, consegue encontrar espaços propícios para a resistência, como sua atuação como exímia jogadora de pôquer, o que lhe permite angariar recursos próprios e abandonar o marido, partindo em busca de sua identidade múltipla e mestiça.

A dominação masculina, que constitui as mulheres como objetos simbólicos, cujo ser é um ser-percebido, tem por efeito colocá-las em estado permanente de dependência simbólica: elas existem primeiro pelo, e para, o olhar dos outros (BOURDIEU, 1999, p. 82). Tal objetivação efetuada pela ótica masculina e patriarcal é tema do conto Mirándola dormir, que 
reelabora a história de Guilhermina Cezar (1870-1936), personagem histórica que, assim como Manuela, se casa muito jovem, precisamente aos quinze anos, com um homem de quarenta anos, Eduardo Wilde (1844-1913), médico e ministro da Justiça e do Interior durante o governo do presidente Julio Roca (1843-1914). Os dois homens mantiveram uma longa amizade e historicamente formaram parte de um tácito triângulo amoroso.

A protagonista é retratada dormindo durante quase dois terços do relato, sendo comparada inclusive à Bela Adormecida por seu marido. Ela é descrita através da mirada de seu esposo que, como um voyeur, se deleita em admirar sua beleza quase todas as noites. Para Eduardo Wilde, Guilhermina é sua obra prima, uma adolescente desajeitada com quem se casou há quase dez anos, moldada por ele com perfeição e transformada numa mulher fascinante, graças ao seu trabalho de demiurgo. Como um Pigmalião, ele se considera o artista que moldou uma belíssima estátua viva de marfim, cuja beleza encanta toda a cidade de Buenos Aires, especialmente seu amigo, o presidente Julio Roca. Wilde rememora com deleite a surpresa e a admiração de seu amigo ao ver Guilhermina entrar com ele num salão, dona de si e da admiração de todos.

A reificação da mulher em objeto de culto e de orgulho revela a objetificação das relações amorosas. Como um Pigmalião voyeur, Wilde se satisfaz apenas em observar longamente sua esposa no momento em que ela adquire o perfil de estátua: durante a imobilidade do sono, compartilhando, em algumas ocasiões, a visão da Bela Adormecida com alguns amigos íntimos. O esposo de Guilhermina assume, portanto, a perspectiva masculina e patriarcal, na qual as mulheres são vistas como objetos, ou melhor, como símbolos cujo sentido se constituiria fora delas, e cuja função seria contribuir para o aumento do capital simbólico em poder dos homens. A beleza da esposa constitui esse capital simbólico que Wilde se deleita em ostentar e que lhe glorificaria a virilidade.

A narrativa apresenta um salto temporal de sete anos e Guilhermina é novamente objeto de admiração durante o sono, desta vez observada por seu amante, o presidente Júlio Roca, que encara com pesar o fim do longo relacionamento deles, em virtude de estar ocupando pela segunda vez a presidência e não poder se expor a um escândalo. Ele então se pergunta se Guilhermina teria se tornado uma mulher deslumbrante, viajada e instruída, sem a mediação de seu amigo Wilde. Tomando para si o papel de demiurgo, Roca conclui que a evolução de sua amante se deve não apenas a seu próprio esforço, mas "graças a ele, Guilhermina tinha deixado de ser essa hierática figurinha dourada (...), para converter-se em um corpo vivo e ativo, (...) um instrumento poderoso (...) que Wilde se limitava a exibir (...), mas que seguramente teria sido incapaz de arrancar-lhe uma só nota" (LOJO, 2011, p. 334, 
trad. nossa).

Júlio Roca opta por abandonar Guilhermina por outra "mulher de pedra": a nação argentina, que ele imagina como uma deusa de mármore, destituída da pele cálida de Guilhermina, mas imune à passagem do tempo. Para assegurar o fim do relacionamento, Roca concede um cargo diplomático para Eduardo Wilde na Bélgica, onde Guilhermina poderia representar a pátria argentina de modo mais gracioso do que uma escultura, embora suspeite que "tanto sua pátria de mármore como Guilhermina tenham o mesmo sorriso de esfinge" (LOJO, 2011, p. 335, trad. nossa). Assim, na objetificação elaborada pelo olhar do amante, Guilhermina tem seu corpo novamente reduzido ao silêncio da figuração muda da estátua.

Observa-se um novo salto temporal de doze anos e finalmente Guilhermina está acordada, olhando serenamente para seu marido que está no leito de morte. O narrador onisciente focaliza, pela primeira vez, os pensamentos e sentimentos de Guilhermina. Ela recorda que aceitou casar-se com o amigo de seu pai, que a tratava como uma irmã menor, porque Wilde lhe deu a oportunidade de se libertar do ambiente conservador de sua casa e do internato. Rememora a atuação do marido como um incansável e por vezes irritante professor, que lhe proporcionou uma vida de viagens e conhecimento. Guilhermina então se questiona por que havia decidido substituir este homem, detentor de tanto saber, por outro homem, seu amante Júlio Roca, detentor de todo o poder. Finalmente compreende que sua identidade sempre foi moldada para satisfazer o orgulho e o desejo dos dois homens que a amaram e também a objetificaram, de modos distintos.

Sua trajetória, portanto, evidencia que o poder simbólico só pode ser exercido com a colaboração dos subalternizados; no caso, as mulheres, que agem sob o domínio das formas prescritas pelo poder patriarcal, disseminadas e inscritas em seus corpos. No final do conto, ao mirar sua própria imagem no espelho, Guilhermina se vê pela primeira vez como sujeito ativo, dona de seu destino e de seu corpo, cuja identidade doravante será moldada por ela própria e nunca mais objeto do controle e da idealização masculinos.

\section{CONSIDERAÇÕES FINAIS}

Podemos concluir que as narrativas de María Rosa Lojo analisadas neste artigo ressignificam as subjetividades femininas, bem como seus corpos são configurados como um lugar de resistência, demonstrando o significado político que assumem, ao comprovar que o mito da fragilidade e inferioridade feminina foi construído pelo discurso colonial e patriarcal. São personagens dotadas de relações de sociabilidades alternativas, baseadas em vivências da 
diferença colonial atravessadas por tensões e criatividades. Assim, por meio da emancipação e da subversão das estruturas patriarcais, suas personagens conseguem encontrar espaços propícios para a resistência e novas possibilidades para a constituição de suas subjetividades.

Complexas e multifacetadas, as personagens dos relatos lojianos apresentam identidades em constante trânsito. São índias e cativas, guerrilheiras e curandeiras, que se posicionam pela renúncia e desconstrução de qualquer sentido de identidade fixa. Ao conceder a voz às mulheres subalternizadas, a autora expressa formas alternativas de ser mulher que, a partir um posicionamento político minoritário, foram capazes de questionar as estruturas patriarcais e coloniais.

\section{REFERÊNCIAS}

BOURDIEU, P. A dominação masculina. Rio de Janeiro: Bertrand, 1999.

ESTEVES, A. R. História e memória em María Rosa Lojo (Tributo a Marilene Weinhardt). Revista Letras. Curitiba: UFPR, n. 94, 2016, p. 69-85.

LOJO, M. R. Amores insólitos de nuestra historia. 2. ed. Buenos Aires: Alfaguara, 2011.

LOJO, M. R. El 'género mujer' y la construcción de mitos nacionales: el caso argentino rioplatense. In: ARANCIBIA, J; ROSAS, Y.; DIMO, E. (orgs.). La mujer en la literatura del mundo hispánico. California: Instituto Literário e Cultural Hispânico, 2000, p. 7-31.

LUGONES, M. Rumo a um feminismo decolonial. In: Pensamento feminista: conceitos fundamentais. Rio de Janeiro: Bazar do Tempo, 2019.

MARCARI, M. F. A. O. Otra historia del guerrero y la cautiva: revisão dos mitos fundacionais da literatura argentina. Todas as musas. São Paulo, vol. 7, n. 2, 2016, p. 44-57.

MIGNOLO, W. Historias locais / Projetos globais. Colonialidade, saberes subalternos, pensamento liminar. Trad. Solange Ribeiro de Oliveira. 1. ed. Belo Horizonte: Ed. UFMG, 2020.

ROTKER, S. Cautivas: olvidos y memoria en la Argentina. Buenos Aires: Ed. Planeta, 1999. 